The International Journal of Indian Psychology

ISSN 2348-5396 (e) | ISSN: 2349-3429 (p)

Volume 3, Issue 4, No. 56, DIP: 18.01.006/20160304

ISBN: 978-1-365-23992-2

http://www.ijip.in | July-September, 2016

\title{
Prosocial Behaviour- A Major Determinant of Helping People in Health Emergency
}

\author{
Sajithkumar $\mathrm{P}^{1 *}$, Dr. Ratna Prakash ${ }^{2}$
}

Keywords: Prosocial Behaviour, Health, Determinant, People

Prosocial behaviour refers to the behaviours that benefit people (Penner, Dovidio, Piliavin, \& Schroder, 2005). Prosocial behaviours are performed to benefit others, rather than to benefit the self. Typically, pro-social behaviors are an outgrowth of positive experiences and emotions (Aydinli et al, 2013). Feelings of empathy, compassion, and sympathy are also associated with helping, particularly when individuals recognize a moral obligation to care for others. According to World Health Organization, Pro-social behavior can emerge, however, from traumatic and painful experiences.

Cardiac arrest is a major public health issue, with more than 500000 deaths of children and adults per year even in developed countries. Despite significant scientific advances in care of cardiac arrest victims, there remain striking disparities in survival rates for both in-hospital and out-of-hospital cardiac arrest. It is seen that survival can vary among geographic regions by as much as 6-fold for victims in pre-hospital setting. For out of hospital cardiac arrest victims, the key determinants of survival are the timely performance of first responder or bystander cardiopulmonary resuscitation (CPR) and defibrillation for those in ventricular fibrillation and pulse less ventricular tachycardia. Only a minority of cardiac arrest victims receive potentially lifesaving bystander CPR, thus indicating that there should be some hindrances for the first responders from the general public to perform this in the right time (Bhanji et al, 2015).

Trauma is a major cause of mortality and morbidity in the world without discrimination of developed or developing countries. Injuries-resulting from traffic collisions, drowning, poisoning, falls or burns - and violence - from assault , self-inflicted violence or acts of war-kill more than five million people worldwide annually and cause harm to millions more. They

\footnotetext{
${ }^{1}$ Assistant Professor, Govt. College of Nursing, Kozhikode, Kerala \& PhD Scholar in National Consortium for PhD in Nursing, India

${ }^{2}$ Professor \& Principal, PAL College of Nursing, Nainital, Uttarakhand, India

*Responding Author

(C) 2016 I P Sajithkumar, R Prakash; licensee IJIP. This is an Open Access Research distributed under the terms of the Creative Commons Attribution License (http://creativecommons.org/licenses/by/2.0), which permits unrestricted use, distribution, and reproduction in any Medium, provided the original work is properly cited.
} 
account for $9 \%$ of global mortality, and are a threat to health in every country of the world. For every death, it is estimated that there are dozens of hospitalizations, hundreds of emergency department visits and thousands of doctors' appointments. The major causes of death in trauma accounts to life threatening hemorrhage, airway obstruction, head and spine trauma and other body system trauma. The concept of Golden hour, the initial hour after the occurrence of trauma is vitally important in the prognosis of trauma victims. The recently introduced concept of 'Platinum ten minutes' indicate the need for more faster and appropriate responses from the first responders in trauma most often the members of general public who witness the trauma. The appropriate actions like seeking the help from health providers and law enforcement authorities, quick actions to stop life threatening bleeding, removing airway obstructions and safe transport of victims to the appropriate trauma centre have a great impact on the survival rate of the trauma victims.

One of the major reasons that can determine the way a person respond to such a health emergency can be the Prosocial behavior or the attitude of that person to help the injured. These actions may be motivated by empathy and by concern about the welfare and rights of others, as well as for egoistic or practical concerns, such as one's social status or reputation, hope for direct or indirect reciprocity, or adherence to one's perceived system of fairness. It may also be motivated by altruism, though the existence of pure altruism is somewhat disputed, and falls into philosophical rather than psychological realm of debate. This study explores the pro-social behavior of public in helping in health related emergencies in selected areas of Kerala state.

\section{Problem Statement:}

A study to determine the Prosocial behavior of public in health related emergencies in selected areas of Kerala state.

\section{OBJECTIVES:}

1. Determine the Prosocial behavior of public in health related emergencies

2. Compare the Prosocial behavior of public in helping in health related emergencies residing in rural and urban areas.

3. Find out the association between prosocial behavior and selected socio demographic variables of public.

\section{METHODOLOGY:}

Quantitative non-experimental approach with descriptive survey design was selected for study. The sample consisted of 200 participants from general public and the sampling technique used is non-probability consecutive sampling technique. 
Prosocial Behaviour- A Major Determinant of Helping People in Health Emergency

\section{Data Collection Tools and Technique:}

The tools were Demographic Proforma and the Prosocial Behaviour Assessment Rating Scale. The rating scale used was an investigator prepared 5 point Likert type scale with 18 items. Data collection technique was self-reporting.

\section{Data Analysis:}

The collected data were analysed using descriptive and inferential statistics using SPSS version 17.

\section{RESULTS}

Majority of the study participants were in the age group of 35-40 years. Most of the study participants had college education (65\%). $56 \%$ of the study participants were males. $23 \%$ of them had the previous experience of helping in health related emergencies. Among 200 study participants $79 \%$ had a very favourable prosocial behaviour and $21 \%$ had a moderate prosocial behaviour. None of the participants had a low score in pro social behaviour. There was no significant difference between the prosocial behaviour of people residing in rural and urban areas at 0.05level of significance. There was no significant association between prosocial behavior and selected socio demographic variables of public in health related emergencies at 0.05 level of significance.

\section{INTERPRETATION AND CONCLUSION:}

The findings of this study reveal that the members of general public have a very good prosocial behaviour. Most of them want to extend their helping hands in health related emergencies. Even though the general Public in the state are far behind in the global surge to learn cardio pulmonary resuscitation and other first aid measures, they have a very good prosocial behaviour to help their fellow beings. The participants reported that lack of knowledge and skill in Basic Life Support prevents them from actively intervening during health related emergencies. It is therefore important to use the first responders' service in a fruitful manner by empowering them to do what is most needed in health related emergencies. Health care providers have to play a very important role in the training of lay public in Basic Life Support.

\section{IMPLICATIONS}

One of the major reasons that can determine the way a person responds to a health emergency can be the prosocial behavior or the attitude of that person to help the sick or injured. The individuals who have good prosocial behaviour are willing to extend their helping hands to people. They are easily trainable and can be prepared with skill training through simulation to be excellent first responders. Nurses being the committed health care task force both in hospital and community settings have to extend their knowledge and skills to prepare the public force to achieve the goal of early identification of the health emergency and Basic Life Support. 


\section{REFERENCES}

Aydinli, A., Bender, M., \& Chasiotis, A. (2013). Helping and Volunteering across Cultures: Determinants of Prosocial Behavior. Online Readings in Psychology and Culture, 5(3).http://dx.doi.org/10.9707/2307-0919.1118.

Bhanji F, Donoghue AJ, Wolff MS, Flores GE, Halamek LP, Berman J M, Sinz EH, Cheng A. Part 14: education: 2015 American Heart Association Guidelines Update for Cardiopulmonary Resuscitation and Emergency Cardiovascular Care. Circulation. 2015;132(suppl 2):S561-S573.(Circulation. 2015;132[suppl 2]:S561-S573. DOI: 10.1161/CIR.0000000000000268.

Eisenberg, Nancy; Fabes, Richard A.; Spinrad, Tracy L. (2007). "Prosocial Development". Handbook of Child Psychology. Handbook of Child Psychology.doi:10.1002/9780470147658.chpsy0311. ISBN 0-470-14765-2.

Hankins, M., Biglan, A., Rusby, J.C., Sprague, J., \& Steiber, S. (2010). The relationship of prosociality to psychological and behavioral problems among early adolescents. In preparation.

Jean M. Twenge ,Roy F. Baumeister and C. Nathan DeWall Natalie J. Ciarocco J. Michael Bartels, Social Exclusion Decreases Prosocial Behavior: Journal of Personality and Social Psychology by the American Psychological Association 2007, Vol. 92, No. 1, 56 66

Penner LA, Dovidio JF, Piliavin JA, Schroeder DA; Prosocial behavior: multilevel perspectives. Annu Rev Psychol. 2005;56:365-92.

Wilson, D.S. \& O'Brien, D.T. (2008). Human prosociality from an evolutionary perspective: variation and correlations at a city-wide scale. In preparation.

How to cite this article: P Sajithkumar, R Prakash (2016), Prosocial Behaviour- A Major Determinant of Helping People in Health Emergency, International Journal of Indian Psychology, Volume 3, Issue 4, No. 56, ISSN 2348-5396 (e) | ISSN: 2349-3429 (p), DIP: 18.01.006/20160304, ISBN: 978-1-365-23992-2 